\title{
Los sufijos -ismo $e$-ista en las ediciones del DRAE de la primera mitad del siglo XIX*
}

LAURA MUÑOZ ARMIJO

Universidad Autónoma de Barcelona

\section{INTRODUCCIÓN}

Los sufijos -ismo e -ista presentan en el siglo XIX una situación de gran productividad que se manifiesta muy especialmente en tres áreas léxicas: el léxico político, el léxico social y el léxico periodístico. Estas tres esferas están estrechamente relacionadas, pues la prensa del momento recoge los términos políticos y sociales, de modo que los textos de los artículos periodísticos constituyen un valioso corpus de datos para investigaciones sobre el léxico político y social.

Los estudios realizados por Fernández Lagunilla demuestran que «los procesos de socialización y democratización de la política que tuvieron lugar en Europa a partir de la Revolución Francesa y sobre todo en el siglo XIX» (1999: 12) determinaron muchos aspectos de las sociedades europeas. Sin lugar a dudas, el ambiente político-social de la primera mitad del siglo xix influye en la formación y evolución de las palabras del léxico español. Investigadores del léxico político-social español como Battaner (1977), Ruiz Otín (1983) y Peira (1987) mencionan términos derivados con -ismo e -ista (carlista, jacobinismo, realista), que reflejan la situación política del momento de la sociedad española. Así, por ejemplo, la adjunción del sufijo -ista a bases patronímicas (mendizabalistas, torenistas, isturizistas para referirse a los seguidores de Mendizábal, del Conde de Toreno o de Istúriz), se convierte en un procedi-

* La investigación necesaria para desarrollar este trabajo ha sido parcialmente financiada con la ayuda de la DGICYT para el proyecto «Informatización y actualización del DCECH de J.Corominas y J.A. Pascual» ( $\mathrm{n}^{\circ}$ de referencia BFF2002-04071-C02-01) y con el apoyo del Comissionat per Universitats $i$ Recerca de la Generalitat de Catalunya ( $\mathrm{n}^{\circ}$ de referencia DGR2001SGR-00151). 
miento recursivo para designar el seguimiento hacia la doctrina política de los líderes de este periodo. Del mismo modo, las investigaciones de Azorín (2000 y 2003) evidencian que el léxico político y social se documenta en las ediciones del DRAE del siglo XIX, aunque las progresivas incorporaciones de los derivados en -ismo e -ista no se distribuyen de un modo proporcional a lo largo de este siglo.

El propósito de esta investigación es presentar la historia lexicográfica de los términos incorporados en -ismo e -ista en las seis ediciones del diccionario de la Real Academia Española ( $D R A E)$ en la primera mitad del siglo xix: cuarta edición (DRAE1803), quinta edición ( $D R A E-1817)$, sexta edición ( $D R A E-1822)$, séptima edición (DRAE-1832), octava edición (DRAE-1837) y novena edición (DRAE-1843). Se trata, por un lado, de observar las incorporaciones de las diferentes ediciones y su pervivencia hasta la última edición del DRAE-2001; y, por otro, de estudiar las características gramaticales y semánticas del léxico formado con estos sufijos documentado en la primera mitad del siglo XIX.

En el siglo xix el DRAE cuenta con un total de diez ediciones que no poseen unas mismas características. Mientras que en la primera mitad del siglo xIX se publican seis ediciones, en la segunda mitad sólo aparecen cuatro: décima edición (1852), undécima edición (DRAE-1869), duodécima edición (DRAE-1884) y decimatercia edición (DRAE-1899). Además, el número de incorporaciones que se recogen con las voces derivadas en ismo e -ista en las seis ediciones de la primera mitad del siglo XIX parece ser inferior al de las cuatro ediciones de la segunda mitad de este siglo. Comparando los resultados obtenidos a partir del Nuevo Tesoro Lexicográfico de la Lengua Española (NTLLE), las 160 incorporaciones de nuevos lemas en -ismo e -ista de las ediciones de la primera mitad contrastan con los 392 términos nuevos de las ediciones de la segunda mitad del siglo xIx. El ambiente político-social y cultural de la segunda mitad del siglo xix ejerce una mayor influencia en todos los niveles de la sociedad española (Lagunilla 1999: 12); en el diccionario académico la presencia del entorno político-social de esta época se refleja con un incremento de incorporaciones en ismo e -ista en la segunda mitad del siglo XIX. Así, se documentan más términos, en concreto la diferencia es de 232 voces respecto a la primera mitad del siglo XIX, que se relacionan con la vida política y social de estos años: krausismo (1884), hegelianismo (1914), republicanismo (1899).

La investigación se centra en el estudio de los cambios registrados en los derivados en -ismo e -ista en las seis ediciones del DRAE de la primera mitad del siglo XIX. Así, se detallan los rasgos propios de las diferentes ediciones -número de incorporaciones y eliminaciones, tipo de léxico (político, social o periodístico)-, y sus características gramaticales y semánticas. Además, con el propósito de ofrecer una visión completa de la historia lexicográfica española monolingüe del siglo XIX, se comparan las incorporaciones de las voces en -ismo e -ista de las diferentes ediciones 
del $D R A E$ con las documentadas en otros diccionarios no académicos ${ }^{1}$ de la misma época. Se tienen en cuenta para ello dos obras lexicográficas: el Diccionario de la lengua castellana de Manuel Núñez de Taboada, editado por primera vez en 1825, y el Nuevo diccionario de la lengua castellana de Vicente Salvá fechado en 1846.

Ambas obras representan a mediados del siglo XIX la consolidación de la lexicografía española monolingüe no académica iniciada por Terreros y Pando en el siglo XVIII. Además de Núñez de Taboada y Salvá, las obras de Juan Peñalver (1842) y Adolfo de Castro (1852) forman un grupo heterogéneo de diccionarios que coinciden, como han señalado Azorín (2000 y 2003) y Baquero (1992), en criticar la labor de la Academia ante la escasa introducción de tecnicismos y de voces americanas. En este estudio sólo se han tenido en cuenta los diccionarios mencionados por el hecho de estar informatizados en la versión electrónica en formato DVD del NTLLE.

\section{Características globales de los datos}

El corpus del presente estudio está formado por un total de 160 derivados en -ismo e -ista que constituyen las incorporaciones producidas en las distintas ediciones del $D R A E$ de la primera mitad del siglo XIX. ${ }^{2}$ Para el análisis de estas voces se ha diseñado una estructura de base de datos con diferentes campos (lema, acepción, categoría gramatical, base léxica, etimología, primera documentación, definición y campo léxico) que permite la caracterización de los términos desde una perspectiva diacrónica y sincrónica.

De los 160 lemas, el número de derivados en -ista (un total de 109) es mayor al de los acabados en -ismo (51 voces). Además, los índices numéricos del cuadro 1 muestran que las incorporaciones en el $D R A E$ no se distribuyen de un modo proporcional a lo largo de las ediciones de la primera mitad del siglo XIX:

Cuadro 1

\begin{tabular}{|c|c|c|c|c|c|c|}
\hline \hline EDICIÓN & 1803 & 1817 & 1822 & 1832 & 1837 & 1843 \\
\hline $\mathrm{N}^{\mathrm{o}}$ voces & 89 & 30 & 12 & 6 & 4 & 19 \\
\hline Porcentaje & $55.62 \%$ & $18.75 \%$ & $7.5 \%$ & $3.75 \%$ & $2.50 \%$ & $11.87 \%$ \\
\hline
\end{tabular}

1 Esta denominación es frecuente en la mayoría de investigadores de la historia de la lexicografía española monolingüe para referirse a otras obras lexicográficas que no son normativas como el diccionario académico: Alvar Ezquerra (1996) y Medina Guerra (2003). Otros estudios optan por la denominación lexicografia extra académica: Azorín (2000), Baquero Mesa (1992).

2 En este cómputo de voces en -ismo e -ista no se han tenido en cuenta los términos que no son derivados aún acabando en -ismo o -ista: ametista (1803), devotismo (1803), estabilisísmo (1803), marismo (1803), infidelísmo (1817), artanista (1822), genista (1822S), ansímísmo (1832) y decentismo (1843). 
A lo largo de las seis ediciones del $D R A E$ de la primera mitad del siglo xIX, el mayor número de incorporaciones en -ismo e -ista se documenta en la cuarta edición (1803) que cuenta con 89 voces nuevas con respecto a la edición de 1791. De acuerdo con las cifras del cuadro 1, la diferencia de voces de la quinta edición (DRAE-1817) con 30 términos nuevos, respecto a la edición anterior de 1803 con 89 voces, es casi superior al triple. Frente a este destacado predominio de la cuarta edición, en las siguientes ediciones el número de incorporaciones desciende a partir de la quinta (DRAE-1817) hasta la octava (DRAE-1837), que representa la edición con un menor número de incorporaciones (sólo 4). En cada una de estas cuatro ediciones, de la quinta (DRAE-1817) a la octava (DRAE-1837), la reducción de voces es equivalente a la mitad: así, por ejemplo, de 30 voces en 1817 se pasa a 12 términos en la edición de 1822. En contraste con la repetida disminución de voces en -ismo e -ista a partir de la quinta edición (DRAE-1817), en la novena edición (DRAE-1843) esta tendencia se rompe y la recepción de este tipo de derivados aumenta (19 voces) respecto a la edición anterior (DRAE-1837).

El recuento de incorporaciones en -ismo e -ista que se desprende del cuadro 1 puede extenderse al resto del léxico recogido en los diccionarios de la Academia, pues los cálculos Alvar (1982: 222) sobre el número de entradas de las distintas ediciones del $D R A E$ coinciden con los resultados del cuadro 1: el número de entradas crece enormemente en la cuarta edición (1803), pues se pasa de 46000 en el DRAE-1791 a 59000 en el DRAE-1803. ${ }^{3}$

\section{ANÁLISIS DE LAS VOCES DEL CORPUS}

\subsection{Caracterización general}

Desde una perspectiva gramatical, los derivados en -ismo son sustantivos y los derivados en -ista pueden tener distintas categorías gramaticales: sustantivos, adjetivos o bien derivados que funcionan a la vez como sustantivos y adjetivos. Otro rasgo gramatical que caracteriza las voces del corpus es el tipo de base léxica. La mayor parte de los términos son derivados formados a partir de bases que son nombres comunes y nombres propios.

3 Los recuentos del número de entradas en las ediciones de la primera mitad del siglo XIX que enumera este autor son los siguentes: 59000 en la $4^{\mathrm{a}}$ ed. (DRAE-1803), 61000 en la $5^{\mathrm{a}}(D R A E-1817)$, 58000 en la $6^{\mathrm{a}}(D R A E-1822), 52000$ en la $7^{\mathrm{a}}(D R A E-1832)$ y $8^{\mathrm{a}}(D R A E-1837)$ y, finalmente, 53000 en la $9^{a}$ (DRAE-1843). Los datos de Morales (2002: 2280), sobre la documentación del diccionario académico en el $D C E C H$, también señalan que la cuarta edición (DRAE-1803) presenta un mayor número de incorporaciones, 56 en total, respecto al resto de ediciones de la primera mitad del siglo XIX. 
Desde el punto de vista semántico, la mayor parte de los derivados en -ismo designan doctrinas de diferentes esferas: políticas, económicas, científicas, religiosas y artísticas; o se refieren a comportamientos humanos (egoísmo). En líneas generales, los derivados en -ista designan básicamente profesiones y partidarios de las doctrinas que se forman con la adjunción de -ismo. Así, se han encontrado parejas de derivados en -ismo e -ista que se refieren respectivamente a una doctrina y a su seguidor (absolutismo - absolutista, jansenismo - jansenista).

Finalmente, otra de las características generales que comparte este tipo de léxico es la de continuar vigente en la actualidad. De las 160 voces del corpus tan solo 12 de ellas no se documentan en la vigésima segunda edición del DRAE-2001: algebista (DRAE-1817), ${ }^{4}$ algibista (DH-1933), aurifabrista (DRAE-1984), cigarrista (DRAE1899), contradancista (DRAE-1837), escuadronista (DRAE-1992), galbanismo (DRAE-1843), gramatista (DRAE-1817), guargarismo (DRAE-1817), meteorista (DRAE-1817), quimista (DRAE-1992) y rodista (DRAE-1869). Algunos de estos lemas desaparecen del $D R A E$ porque son voces que remiten en su definición a un sinónimo que se ha consolidado en la actualidad. Este es el caso de algebista / algibista que remiten al término algebrista y de las voces aurifabrista, guargarismo, quimista y rodista cuyos sinónimos remitidos son respectivamente orífice, gargarismo, alquimista y rodio. Los términos contradancista, escuadronista, galbanismo y meteorista son voces técnicas que posiblemente se dejaron de usar a partir de una época determinada $y$, por este motivo, no se documentan en la actualidad.

\subsection{Características de la microestructura: acepciones y definiciones}

La mayoría de los lemas del corpus tiene una única acepción. De las 160 voces del corpus, sólo dos de ellas tienen dos acepciones: gacetista ${ }^{5}(D R A E-1817)$ y realis$t a^{6}(D R A E-1803)$.

Las características más interesantes de la microestructura se observan en el contenido de las definiciones de los lemas. En primer lugar, en la redacción de las definiciones destaca un notable grado de subjetivismo, especialmente en las voces que designan una doctrina de cualquier esfera de la sociedad y en los partidarios o seguidores de dicha ideología cuando no siguen una tendencia purista y conservadora. Así, las voces del corpus con este significado -deísmo, molinista, politeísmo, quietismo, etc.- aparecen descritas con matices subjetivos negativos del tipo: «error

4 La fecha entre paréntesis corresponde a la última documentación del lema.

5 Las dos acepciones son: 1) «El que habla frecuentemente de novedades». 2) «El que tiene costumbre, inclinación o propensión á leer ú oir las gacetas».

${ }^{6}$ Las dos acepciones son: 1) «El que en las guerras civiles sigue el partidario de los reyes». 2) «El que defiende las regalías, derechos y prerrogativas de los soberanos». 
de los que creen [...]», «el que sigue los errores de Molinos, herege del siglo décimo séptimo $[\ldots]$... La intromisión de la ideología conservadora de la corporación se percibe sobre todo en los lemas que designan doctrinas religiosas que son contrarias a la religión católica (fatalismo, luteranismo, maniqueísmo), voces que dañan la moral cristiana por no compartir sus creencias y que son definidas con la palabra despectiva «secta» que evidencia el subjetivismo de la Corporación, un rasgo en el que ya había reparado Azorín (2000: 265). Esta investigadora destaca que la intromisión de elementos ideológicos ajenos al contenido del definido en las ediciones del DRAE de la primera mitad del siglo XIX, es duramente criticada por lexicógrafos como Núñez de Taboada o Salvá.

En segundo lugar, otra de las características observadas en las definiciones es el uso de sinónimos; esto es, definiciones que remiten a otro lema. En el cuadro 2 aparecen las diecisiete parejas formadas por la voz incorporada y la voz remitida, registradas en el corpus:

Cuadro 2

\begin{tabular}{||c|c|}
\hline VOZ INCORPORADA & VOZ REMITIDA \\
\hline algebista $(D R A E-1803)$ & algebrista $(D A-1726)$ \\
\hline algibista $(D R A E-1803)$ & algebrista $(D A-1726)$ \\
\hline aurifabrista $(D R A E-1803)$ & orifice $(D A-1737)$ \\
\hline fachendista $(D R A E-1803 S)$ & fachenda $(D R A E-1803 S)$ \\
\hline guargarismo $(D R A E-1803)$ & gargarismo $(D A-1734)$ \\
\hline lamparista $(D R A E-1803)$ & lamparero $(D A-1734)$ \\
\hline luismo $(D R A E-1803)$ & laudemio $(D A-1734)$ \\
\hline metalista $(D R A E-1803)$ & metalario $(D A-1734)$ \\
\hline pasionista $(D R A E-1803)$ & pasionero $(D R A E-1780)$ \\
\hline pirronismo $(D R A E-1803)$ & escepticismo $(D R A E-1791)$ \\
\hline quimista $(D R A E-1803)$ & alquimista $(D A-1770)$ \\
\hline sofismo $(D R A E-1803)$ & sofisma $(D R A E-1780)$ \\
\hline cuadrivista $(D R A E-1817)$ & matemático $(D R A E-1780)$ \\
\hline estajista $(D R A E-1817)$ & destajero $(D A-1732)$ \\
\hline destajista $(D R A E-1822)$ & destajero $(D A-1732)$ \\
\hline rodista $(D R A E-1832)$ & rodio $(D R A E-1803)$ \\
\hline islamismo $(D R A E-1843)$ & mahometismo $(D A-1734)$ \\
\hline \hline
\end{tabular}

Las voces incorporadas en las ediciones anteriores a 1822 se definen con los sinónimos que figuran en la columna derecha del cuadro 2, con una fórmula introductoria en la redacción del tipo «lo mismo que». Alvar Ezquerra (1982: 233) 
señala que «en la sexta edición (1822) se corrigieron las definiciones sinonímicas, evitando la fórmula introductoria que se venía empleando: lo mismo que» y, efectivamente, las voces del corpus definidas con un sinónimo no utilizan esta fórmula a partir de 1822. Así, la generalización de Alvar Ezquerra se cumple en las voces destajista (DRAE-1822), rodista (DRAE-1832) e islamismo (DRAE-1843) que remiten directamente al sinónimo sin usar la expresión citada.

De acuerdo con las fechas que aparecen en el cuadro 2, en los diecisiete lemas que se definen mediante un sinónimo, la voz remitida es cronológicamente anterior al lema de la entrada léxica del diccionario: nueve de los sinónimos (algebrista, alquimista, destajero, gargarismo, lamparero, laudemio, mahometismo, metalario y orífice) se documentan en las ediciones del DA; tres de ellos (matemático, pasionero y sofisma), en la primera edición del $D R A E$ del siglo XVIII (DRAE-1780); uno (escepticismo), en la tercera edición (DRAE-1791) y dos (fachenda y rodio), en la cuarta edición (DRAE-1803). De estos datos se deduce que las voces remitidas tienen una historia lexicográfica anterior ya que, casi en su totalidad, tienen un siglo más de vida en comparación con la entrada del lema del diccionario que se incorpora en la primera mitad del siglo XIX.

En la evolución de ambas voces se observan dos tipos de relaciones diferentes entre el término incorporado y el remitido, en las ediciones posteriores del DRAE. En un primer grupo, se encuentran seis parejas de voces en las que las palabras incorporadas no han pervivido $\mathrm{y}$, en cambio, se ha consolidado la voz remitida presente desde el siglo XVIII en el $D A$. En estos casos las voces incorporadas son variantes de las voces remitidas: algebista y algibista son variantes de la voz remitida algebrista que se mantiene en la vigésima segunda edición (DRAE-2001). Lo mismo ocurre con los términos aurifabrista, guargarismo, quimista y rodista que remiten respectivamente a las voces que se han consolidado en la actualidad orifice, gargarismo, alquimista y rodio.

En un segundo grupo, ambos tipos de voces se han consolidado hasta nuestros días: la incorporada en el siglo XIX y el sinónimo remitido del siglo XVIII. Diez parejas de términos, mencionadas en el cuadro 2 , mantienen esta relación de pervivencia en la actualidad: ${ }^{7}$ fachendista $\rightarrow$ fachenda, lamparista $\rightarrow$ lamparero, luismo $\rightarrow$ laudemio, metalista $\rightarrow$ metalario, pasionista $\rightarrow$ pasionero, pirronismo $\rightarrow$ escepticismo, sofismo $\rightarrow$ sofisma, cuadrivista $\rightarrow$ matemático, destajista / estajista $\rightarrow$ destajero, islamismo $\rightarrow$ mahometismo. En estas diez parejas se distinguen voces que son variantes del término remitido y que tienen un mismo significado al de la voz remitida -como en destajista / estajista $\rightarrow$ destajero, metalista $\rightarrow$ metalario, pasionista $\rightarrow$ pasionero-, y palabras

${ }^{7}$ El símbolo $\rightarrow$ señala la voz remitida que se usa para definir la voz incorporada en la segunda mitad del siglo XIX. 
en las que la voz incorporada no es una variante de la voz remitida sino que es un término nuevo que designa un significado semejante al de la voz remitida: cuadrivista $\rightarrow$ matemático, pirronismo $\rightarrow$ escepticismo. En la vigésima segunda edición (DRAE2001), algunas de estas voces siguen remitiendo a las mismas palabras que en la edición en la que se incorporan en el siglo xix: lamparista $\rightarrow$ lamparero y luismo $\rightarrow$ laudemio; en cambio, en otras palabras se producen nuevas remisiones en las que aparecen otras voces. Así, metalario remite a metalero.

Otro de los rasgos que se observa en las definiciones de los lemas del corpus es la ausencia de información sobre el origen de las palabras. Este dato no resulta relevante, ya que las referencias etimológicas no aparecen en el $D R A E$ hasta finales del siglo XIX, a partir de la duodécima edición (DRAE-1884; Alvar Ezquerra 1982: 232). Sólo en dos lemas del corpus se indica una información sobre su procedencia que simplemente denota que la palabra era sentida como un extranjerismo: gramatista (DRAE-1803), «Voz puramente latina», y nepotismo (DRAE-1843), «Voz italiana».

\subsection{Información gramatical}

\subsubsection{Morfología}

El tipo de derivación de las voces en -ismo no es la misma que la de los derivados en -ista. La derivación de los términos en -ismo es de tipo nominal, ya que la categoría resultante del proceso derivativo es un sustantivo. En cambio, la derivación a partir de la adjunción del sufijo -ista puede ser de tipo nominal y adjetival. Este sufijo produce términos que pueden ser nombres, adjetivos y, en algunas ocasiones, funcionan a la vez como un sustantivo y un adjetivo. En el corpus, el número de sustantivos en -ista asciende a un total de 88 derivados (helenista), el de adjetivos en -ista a 11 términos (absolutista, rodista) y, finalmente, se encuentran 10 lemas en ista que son adjetivos y también funcionan como sustantivos (donatista, petrarquista). En las definiciones de estos lemas que pueden funcionar como adjetivos y sustantivos se especifican indicaciones morfológicas que informan al usuario acerca de las categorías gramaticales: «Adjetivo.[...] Úsase también como substantivo».

Un segundo aspecto morfológico observado en los términos de nuestro corpus es la presencia de algunos tipos de bases que se repiten con frecuencia para crear los derivados. La primera clase de base léxica más frecuente a la que se adjuntan los sufijos -ismo e-ista son los nombres comunes que tienen una base adjetiva (absolutista, clasicismo) o sustantiva (articulista, folletista). El segundo tipo corresponde a los nombres propios (galenista, priscilianismo). El número total de bases léxicas que son nombres comunes es 131 y el de bases patronímicas corresponde a 20 casos. De estas 20 bases patronímicas se cuentan 8 casos de derivados en -ismo (jansenismo, molinismo) y 12 en -ista (maquiavelista, petrarquista). La mayor parte de las incor- 
poraciones formadas a partir de nombres propios datan del DRAE-1803 (17 casos). ${ }^{8}$ En cambio, en el resto de ediciones de la primera mitad del siglo XIX las incorporaciones de este tipo de derivados son menores: tres casos (jansenista, jansenismo, pelagianismo) en la quinta edición (DRAE-1817) y un caso (tomista) en la séptima edición (DRAE-1832).

\subsection{Información semántica: clasificaciones semánticas}

La presente investigación ha permitido establecer una clasificación semántica de las voces incorporadas en la primera mitad del siglo XIX. En el apartado «campo léxico» de la base de datos se han recogido los principales campos semánticos a los que se adscriben los derivados en -ismo e -ista incorporados en el DRAE en este periodo. En el cuadro 3 aparece la distribución de voces en cada uno de los campos léxicos:

Cuadro 3

\begin{tabular}{|c|c|c|}
\hline CAMPO LÉXICO & $\mathrm{N}^{\mathbf{0}}$ DE VOCES & EJEMPLOS \\
\hline IDEOLOGÍA O DOCTRINA (-ISMO) & 40 & \\
\hline Religión & 15 & maniqueísmo, tolerantismo \\
\hline Ciencia & 14 & empirismo, estrabismo \\
\hline Política & 8 & patriotismo, feudalismo \\
\hline Arte & 3 & aticismo, purismo \\
\hline PARTIDARIOS DE LAS IDEOLOGÍAS (-ISTA) & 27 & \\
\hline Religión & 7 & donatista, evangelista \\
\hline Ciencia & 7 & gasendista, tomista \\
\hline Política & 8 & absolutista, jansenista \\
\hline Arte & 5 & contradancista, petrarquista \\
\hline PROFESIONES & 59 & articulista, folletista \\
\hline ACTITUDES & 14 & bromista, fachendista \\
\hline DEPORTES & 1 & bañista \\
\hline TERMINOLOGÍA LingÜÍSTICA & 6 & galicismo, helenismo \\
\hline Gentilicios & 1 & rodista \\
\hline
\end{tabular}

De acuerdo con las investigaciones realizadas sobre los sufijos -ismo e -ista, ${ }^{9}$ los principales significados de ambos sufijos son los que se recogen en el cuadro 3. La mayoría de los derivados en -ismo se refieren a una doctrina y los términos en -ista

8 Las 17 voces son arrianismo (DRAE-1803S), donatista, galenista, gasendista, luteranismo, mahometista, maquiavelismo, maquiavelista, molinismo (DRAE-1803S), molinista (DRAE-1803S), petrarquista, pirronismo, priscilianismo, priscilianista, sanjuanista, santiaguista y semipelagianismo.

9 Vid. Beniers (1992), Lang (1992), Pharies (2002), Rainer (1999) y Santiago Lacuesta y Bustos (1999). 
nombran principalmente oficios. Para Pharies estos significados son las principales designaciones de los sufijos -ismo e -ista: «por un lado, los derivados en -ista designan a personas que ejercen una profesión u oficio [...] y por otro, partidarios de doctrinas de varios tipos, como religiosas, artísticas y científicas» (2002: 358). Así, un número elevado de los lemas del corpus, 40 términos, remite a diferentes tipos de ideologías (destacan las religiosas, las científicas y las políticas) y, en cambio, el número de voces que designan a los partidarios de estas doctrinas es menor, 27 lemas. Según los datos del cuadro 3 , los derivados en -ista que designan profesiones presentan una cantidad mayor de voces, 59 en total, que los derivados en -ista que designan a los partidarios de las ideologías, 27 voces. De las 59 profesiones que se introducen en las ediciones del $D R A E$ de la primera mitad del siglo XIX, ${ }^{10}$ destaca un número elevado de voces, en concreto 22 , que pertenecen al área de la literatura y la prensa (diarista, gacetista, mitologista). En la misma proporción, con un total de 21 voces, se encuentra el tipo de profesiones que corresponden a trabajos manuales; esto es, oficios que necesitan una elaboración manual para la obtención de productos (licorista, diamantista, hojaldrista). Con un porcentaje menor, 11 profesiones se relacionan con actividades económicas (capitalista, economista, prestamista).

Finalmente, se encuentran pocas voces relacionadas con profesiones que pertenecen al área de la ciencia (dos voces: meteorista, mineralogista), la música (dos voces: bajonista, instrumentista) y a la esfera del deporte (sólo un caso: agiotista).

\subsection{Parejas -ismo / -ista}

En los derivados del corpus se observa una relación de dualidad entre -ismo e -ista. De acuerdo con esta correspondencia - esto es, a un derivado en -ismo le suele corresponder otro derivado en -ista-, algunos investigadores ${ }^{11}$ designan la relación entre -ismo e -ista con las denominaciones de dobletes, de sistema por parejas o de paradigma derivativo. En el corpus de la presente investigación se encuentran trece parejas en -ismo e -ista, que se han incorporado en la misma edición del DRAE:

deísmo-deísta (DRAE-1803S), fatalismo-fatalista (DRAE-1803S), helenismo-helenista (DRAE-1803), maquiavelismo-maquiavelista (DRAE-1803), materialismo-materialista (DRAE-1803), molinismo-molinista (DRAE-1803S), priscilianismo-priscilianista (DRAE-1803), purismo-purista (DRAE-1803), quietismo-quietista (DRAE-1803), rigorismo-rigorista (DRAE-1803), egoísmo-egoísta (DRAE-1817), jansenismo-jansenista (DRAE-1817), absolutismo-absolutista (DRAE-1843).

1029 incorporaciones en el DRAE-1803, 13 en el DRAE-1817, 6 en el DRAE-1822, 2 en el DRAE1832,3 en el DRAE-1837 y 6 en el DRAE-1843.

11 Vid. Battaner (1977), Cabré y Rigau (1985), Peira (1987), Beniers (1992), Lang (1992), Alvar Ezquerra (1993), Castillo Carballo (1993) y Blanco (1996). 
En cambio, se encuentra la pareja mahometista (DRAE-1803) - mahometismo ( $D A-1734)$, en la que el primer miembro se incorpora en alguna de las ediciones de la primera mitad del siglo xIX y el otro, es anterior.

Normalmente, el sistema de parejas -ismo / -ista se cumple en los derivados que designan una doctrina (acabados en -ismo) y a sus partidarios (acabados en -ista). De acuerdo con Battaner (1977), los dobletes -ismo/-ista son frecuentes en derivados creados a partir de bases patronímicas. En las parejas encontradas en el corpus se encuentra esta tendencia pero también se forman a partir de nombres y adjetivos comunes (absolutismo - absolutista).

4. Comparación de las ediciones del DRAE de la PRimera mitad Del XiX CON LoS DiCCIONARIOS NO ACADÉMICOS DE NúÑEZ DE TABOAdA (1825) y SALVÁ (1846)

Las obras de Núñez de Taboada y Salvá presentan un mayor número de incorporaciones de lemas en -ismo e -ista que las ediciones del DRAE. Tras realizar una serie de cálculos, comparando las entradas que figuran en cada uno de estos diccionarios, los datos que marcan la diferencia de voces entre estos dos autores y las ediciones del $D R A E$ son los siguientes: la obra de Núnez de Taboada recoge unas 50 voces más que el $D R A E$ en su sexta edición $(D R A E-1822)^{12} \mathrm{y}$, en cambio, el diccionario de Salvá contiene unos 100 términos más que la novena edición $(D R A E-1843)^{13}$ del diccionario académico. Estos datos confirman que el número de palabras compartidas en estas tres obras es mayor al de voces no compartidas.

En primer lugar, destacan las voces que comparte el $D R A E$ con cada uno de estos dos diccionarios no académicos. 384 voces de la sexta edición del diccionario académico aparecen en la nomenclatura de la obra de Núñez de Taboada; y por su parte el $D R A E$ presenta 413 términos que son comunes al diccionario de Salvá hasta la edición de 1843. En segundo lugar, los dos lexicógrafos mencionados presentan un alto número de términos en común. De las 529 voces en -ismo e -ista del diccionario de Salvá, 302 son comunes a la obra de Núñez de Taboada. Este dato está en consonancia con lo que señala Baquero (1992: 455), sobre la influencia que ejerce la labor de Núñez de Taboada en la elaboración del diccionario de Salvá.

Finalmente, existe un grupo de términos que se han considerado aportaciones propias de los dos lexicógrafos, pues son voces que no comparten ambos autores y que, además, no se documentan en las ediciones del $D R A E$. El número de voces pro-

12 Hasta el DRAE-1822 se han contado un total de 384 incorporaciones en -ismo e -ista que contrastan con las 441 de Núñez de Taboada.

13 Hasta la novena edición (DRAE-1843) se cuentan 413 lemas, que contrastan con los 529 términos de Salvá. 
pias del diccionario de Núnez de Taboada asciende a 31, mientras que en la obra de Salvá se cuentan 96 lemas originales.

Algunas de las aportaciones propias de cada uno de estos dos autores forman parte de la nomenclatura del $D R A E$ en las ediciones posteriores de la segunda mitad del siglo XIX y del Xx. En cambio, existen otras palabras que nunca han sido acogidas en el diccionario académico. De las 31 voces propias de la obra lexicográfica de Núñez de Taboada, 15 de ellas se documentan en el $D R A E$ después de 1825 (6 en el $D R A E-1869,2$ en el $D R A E-1884,2$ en el $D R A E-1899,1$ en el $D R A E-1914,2$ en el $D R A E-1925,1$ en el $D R A E-1970$ y 1 en el $D R A E-1984) ;{ }^{14} \mathrm{y}$, en el caso de las voces propias de Salvá, de los 96 términos 54 se recogen en el $D R A E$ a partir de 1846 (10 en el $D R A E-1852,11$ en el $D R A E-1869,7$ en el $D R A E-1884,3$ en el $D R A E-1899,3$ en el $D R A E-1914,7$ en el $D R A E-1925,4$ en el $D M I L E-1927,2$ en el $D R A E-1933,4$ en el $D R A E-1936,2$ en el $D R A E-1984$ y 1 en el $D M I L E-1989) .{ }^{15}$ Estos datos muestran la modernidad de los diccionarios de Núñez de Taboada y Salvá. Además, la mayoría de estas voces han pervivido hasta la actualidad.

Entre las voces que nunca se han documentado en el $D R A E$, destacan los 16 términos de la obra de Núñez de Taboada y los 42 del diccionario de Salvá. En este conjunto de voces que no comparten los citados lexicógrafos con el $D R A E$, palabras que no se han consolidado en el léxico español, se observan cuatro tipos de términos en -ismo e -ista. En los dos primeros, se encuentran voces vulgares y familiares de la lengua común que la Corporación no los documenta en ninguna edición -como cabronismo (Salvá), chabacanismo (Salvá), chupatismo (Salvá), muchachismo (Salvá) y trajinista (Salvá)-y neologismos del léxico científico y técnico, que posiblemente no tuvieron mucho éxito en el vocabulario español y, por esta razón, no aparecen en el DRAE: cabriolista (Salvá), fisiologista (Salvá), inoculista (Taboada) y sexcentista (Salvá). En un tercer grupo, se encuentran variantes en -ismo e -ista de otras palabras que no se han consolidado en el DRAE. Así, epicurismo (Salvá) y dialogista (Salvá) son variantes de los términos epicureísmo y dialoguista. Estos últimos se han consolidado y continúan apareciendo en el $D R A E$-2001 En la última clase de términos, se agrupan las voces de Núñez de Taboada y Salvá que en el $D R A E$ aparecen expresadas con otros sufijos. Las voces corsarista (Salvá), curialista (Salvá), monarquista (Taboada) y virgilista (Salvá) de los diccionarios no académicos, se documentan en el DRAE adjuntados respectivamente a otros sufijos: corsario, curialesco, monárquico y virgiliano. ${ }^{16}$

14 Algunos ejemplos son balista (DRAE-1884), harmonista (DRAE-1899), tomismo (DRAE-1914) y noctambulismo (DRAE-1925).

15 Algunos ejemplos son pianista (DRAE-1852), sincronismo (DRAE-1884), tropelista (DRAE1914) y virotismo (DRAE-1925).

16 Las primeras documentaciones de estos cuatro términos son: corsario (DRAE-1780), curialesco (DRAE-1925), monárquico (DRAE-1780) y virgiliano (DRAE-1803). 
El hecho de que algunas de las voces originales de estos dos autores no se documenten en el $D R A E$ evidencia que los dos diccionarios estudiados hayan partido de otros criterios, diferentes al $D R A E$, para la recepción de los derivados en -ismo e -ista. Ambas obras comparten el afán de superar al $D R A E$ en el número de entradas y, de acuerdo con este objetivo, incorporan una mayor cantidad de voces, aunque no se conozcan plenamente en el léxico español. En algunos casos, la Corporación incorpora algunos de estos términos en ediciones posteriores de la segunda mitad del siglo XIX y del siglo XX.

\section{CONCLuSiones}

De las seis ediciones que presenta el $D R A E$ en la primera mitad del siglo xIX, la cuarta edición (DRAE-1803) es la que cuenta con un mayor número de incorporaciones en -ismo e -ista; la cifra asciende a 89 voces que representa un $55.62 \%$ de los 160 derivados que se documentan en las ediciones del $D R A E$ de este periodo. En el resto de ediciones los porcentajes son inferiores hasta la octava edición ( $D R A E-1837)$, que sólo presenta 4 lemas, y en la novena edición ( $D R A E$-1843) se observa un ligero aumento de términos (19 voces).

Los 160 lemas del corpus son sustantivos y adjetivos formados a partir de bases que pertenecen a la clase de los nombres comunes y propios. Desde el punto de vista semántico, los derivados en -ismo nombran principalmente ideologías (40 voces) de tipo religioso, científico y político, y los términos en -ista designan oficios (59 términos) que se engloban en tres áreas profesionales: literatura, prensa y trabajos manuales. Los derivados en -ismo, creados a partir de una base patronímica, que designan doctrinas suelen tener su correspondiente pareja en -ista para nombrar al partidario de esa ideología. Una última característica de las voces del corpus es el subjetivismo de la Corporación que se observa en las definiciones de los derivados en -ismo e -ista que se relacionan con una doctrina religiosa o científica distintas a la concepción católica. En relación a los rasgos de las definiciones, se usan sinónimos y remisiones a otras palabras, que cronológicamente se documentan en el siglo XVIII, para definir los lemas incorporados.

El número de incorporaciones contadas en los diccionarios no académicos de Núñez de Taboada y Salvá supera las cifras de la Corporación en las seis ediciones de la primera mitad del siglo XIX. El tipo de voces originales, que aparecen en las obras lexicográficas de estos dos autores no académicos -términos vulgares de la lengua común, palabras del vocabulario científico y técnico, variantes de otras palabras, y términos en -ismo e -ista que en el DRAE aparecen con otros sufijos- evidencian la disparidad de criterios de las dos corrientes lexicográficas para la incorporación de voces en -ismo e -ista. 


\section{REFERENCIAS BIBLIOGRÁFICAS}

Alvar Ezquerra, Manuel (1982): «El Diccionario de la Academia en sus prólogos», en M. Alvar Ezquerra (1993), Lexicografía descriptiva, Barcelona, Bibliograf, pp. 215-241.

- (1993): La formación de palabras en español, Madrid, Arco/Libros.

Azorín FernánDEZ, Dolores (1996-97): «La lexicografía española en el siglo Xix: del diccionario a la enciclopedia», Estudios de Lingüística, 11, pp. 111-122.

- (2000): Los diccionarios del español en su perspectiva histórica, Alicante, Universidad de Alicante.

- (2003): «Neologismos incorporados por Salvá en el Nuevo Diccionario de la Lengua Castellana», Estudios de Lingüística, 17, pp. 107-139.

Battaner Arias, Ma Paz (1977): Vocabulario político-social en España (1868-1873), Madrid, Anejos del Boletín de la Real Academia Española.

Baquero Mesa, Rosario (1992): «Notas en contribución a la historia de la lexicografía española monolingüe del siglo XIX», en Euralex'90 Proceedings. Actas del IV Congreso Internacional, Barcelona, Bibliograf, pp. 455-461.

Beniers, Elisabeth (1992): «El sufijo -ismo en el español de México», en Scripta Philologica (In Honorem Juan M. Lope Blanch), México, UNAM, II, pp. 313-337.

Blanco, Luisa (1996): «El español actual. Tendencias sufijales», en Ma do Carmo Henríquez y Antonio Rifón, eds., Estudios de Morfología, Vigo, Departamento de Filología Española de la Universidad de Vigo, pp. 9-26.

Cabré, Ma Teresa i Gemma Rigau (1986): Lexicologia i semántica, Barcelona, Enciclopedia Catalana.

Castillo Carballo, MaAuxiliadora et al. (1993): «Los neologismos por derivación y composición en el lenguaje periodístico», Verba, 20, pp. 413-423.

Fernández Lagunilla, Marina (1999): La lengua en la comunicación política II: La palabra del poder, Madrid, Arco/Libros.

Lang, Mervyn, F. (1992): Formación de palabras en español. Morfología derivativa productiva en el léxico moderno, Madrid, Cátedra.

Morales Ruiz, Carmen (2002): «La documentación del Diccionario Académico en el DCECH», en M Teresa Echenique y Juan Sánchez Méndez, eds., Actas del v Congreso Internacional de Historia de la Lengua Española, Madrid, Gredos, pp. 2275-2286.

Peira Soberón, Pedro (1987): «Contribución al estudio del vocabulario de los partidos políticos (1833-1840)», en In memoriam Inmaculada Corrales, La Laguna, Universidad de la Laguna, I, pp. 383-395. 
RAINER, Franz (1999): «La derivación adjetival», en Ignacio Bosque y Violeta Demonte, dirs., Gramática descriptiva de la lengua española, III. Entre la oración y el discurso. Morfología, Madrid, Espasa-Calpe, pp. 4595-4644.

Ruiz Otín, Doris (1983): Política y sociedad en el vocabulario de Larra, Madrid, Centro de Estudios Constitucionales.

SANTIAGo Guervós, Javier (1989): «La creación de palabras por derivación como característica del vocabulario político de la transición democrática española», Analecta Malacitana, XII/2, pp. 233-241.

Santiago Lacuesta, Ramón y Eugenio Bustos Gisbert (1999): «La derivación nominal», en Ignacio Bosque y Violeta Demonte, dirs., Gramática descriptiva de la lengua española, III. Entre la oración y el discurso. Morfología, Madrid, Espasa Calpe, pp. 4505-4594.

Seco, Manuel (1987): Estudios de lexicografía española, Madrid, Paraninfo.

\section{DiCCIONARIOS}

Castro, Adolfo de (1852): Gran diccionario clásico de la lengua española, Madrid, Seminario Pintoresco y de la Ilustración.

DA. Real Academia española (1726-1739): Diccionario de la lengua castellana, en que se explica el verdadero sentido de las voces, su naturaleza y calidad, con las phrases o modos de hablar, los proverbios o refranes, y otras cosas convenientes al uso de la lengua, Madrid, Imprenta de Francisco del Hierro.

DA-1770. ReAl AcAdemia española (1778²): Diccionario de la lengua castellana compuesto por la Real Academia Española. Segunda impresión corregida y aumentada, Madrid, Joachin Ibarra.

DRAE-1803. Real ACADEMIA española (18034): Diccionario de la lengua castellana compuesto por la Real Academia Española, reducido a un tomo para su más fácil uso, Madrid, Viuda de Joaquín Ibarra.

DRAE-1817. Real Academia española (18175): Diccionario de la lengua castellana por la Real Academia Española, Madrid, Imprenta Real.

DRAE-1822. Real Academia española $\left(1822^{6}\right)$ : Diccionario de la lengua castellana por la Real Academia Española, Madrid, Imprenta Nacional.

DRAE-1832. Real Academia española (18327): Diccionario de la lengua castellana por la Real Academia Española, Madrid, Imprenta Real.

DRAE-1837. Real Academia española $\left(1837^{8}\right)$ : Diccionario de la lengua castellana por la Real Academia Española, Madrid, Imprenta Nacional. 
DRAE-1843. Real Academia española (1843ํ): Diccionario de la lengua castellana por la Real Academia Española, Madrid, Imprenta de D. Francisco María Fernández.

DRAE-2001. Real Academia española (200122): Diccionario de la lengua española, Madrid, EspasaCalpe [versión en CD-ROM].

NúÑEZ DE TABOADA, Manuel (1825): Diccionario de la lengua castellana, para cuya composición se han consultado los mejores vocabularios de esta lengua y el de la Real Academia Española; aumentado con más de 5000 voces o artículos que no se hallan en ninguno de ellos, París, Seguin.

NTLLE. Real Academia española (2001): Nuevo Tesoro Lexicográfico de la Lengua Española, Madrid, Espasa-Calpe [edición en DVD].

Peñalver, Juan (1842): PANLÉXICO, Diccionario Universal de la lengua castellana, Madrid, Imprenta de Ignacio Boix.

Pharies, David (2002): Diccionario etimológico de los sufijos españoles y de otros elementos finales, Madrid, Gredos.

SAlvé, Vicente (1846): Nuevo diccionario de la lengua castellana, que comprende la última edición integra, muy rectificada y mejorada del publicado por la Academia Española, y unas veinte y seis mil voces, acepciones, frases y locuciones, entre ellas muchas americanas [...], París, Vicente Salvá. 